\title{
PENETAPAN KADAR SAKARIN DAN SIKLAMAT YANG TERKANDUNG DALAM SERBUK CAPPUCINO YANG DICAMPUR DAN TIDAK DICAMPUR YANG BEREDAR DI WILAYAH TAPOS DEPOK JAWA BARAT
}

\author{
*Catu Umirestu, Masdianto, Yuli Kristianingsih, Cahyani Putri Pradini \\ ${ }^{1}$ Program Studi Analis Kesehatan, Fakultas Kesehatan, Universitas Mohammad Husni Thamrin \\ Correspondence author:Catu Umirestu Nurdiani, ctani_enan@yahoo.com, Jakarta, Indonesia
}

\begin{abstract}
ABSTRAK
Pangan seperti pewarna, pengawet dan pemanis buatan. Jenis pemanis yang sering digunakan adalah sakarin dan siklamat, dengan tingkat kemanisan pada sakarin 200-700 kali dari rasa manis sukrosa sedangkan tingkat kemanisan siklamat 30 kali dari rasa manis sukrosa, penggunaan sakarin yang berlebihan dan terakumulasi dalam tubuh sehingga dapat memicu tumor kandung kemih, alergi, dan memutuskan plasenta pada bayi.Pemeriksaan ini untuk mengetahui kadar Natrium Sakarin dan Siklamat pada serbuk cappucino dicampur dan serbuk cappucino tidak dicampur yang terjual di wilayah Tapos Depok Jawa Barat secara kualitatif dan kuantitatif dengan metode titrasi asam basa untuk Sakarin dan Gravimetri untuk Siklamat. Hasil dari 10 sampel semua mengandung Sakarin dengan kadar Sakarin tertinggi ada di serbuk cappucino yang sudah dicampur dengan gula yaitu dengan kadar 1154,95 $\mathrm{mg} / \mathrm{kg}$. Dan tidak memenuhi syarat yang tercantum di dalam Perka BPOM RI No 4 Tahun 2014 yaitu $100 \mathrm{mg} / \mathrm{kg}$, pada pemanis Siklamat dari 10 sampel ada 4 sampel menunjukkan hasil positif. 2 sampel tidak memenuhi syarat sesuai dengan Perka BPOM RI No 4 Tahun 2014 yaitu melebihi $250 \mathrm{mg} / \mathrm{kg}$. Sedangkan pada hasil Uji T Sakarin didapatkan hasil $\mathrm{H}_{0}$ diterima yang berarti kadar Sakarin pada serbuk cappucino dicampur dan tidak dicampur sama atau tidak ada perbedaan. Pada pemeriksaan Siklamat didapatkan hasil $\mathrm{H}_{0}$ diterima yang berarti bahwa kadar siklamat pada serbuk cappucino dicampur dan tidak dicampur sama atau tidak ada perbedaan.
\end{abstract}

Kata kunci : Sakarin,Siklamat,Titrasi Asam Basa dan Gravimetri

\section{ABSTRACT}

Foods such as dyes, preservatives and artificial sweeteners. Types of sweeteners that are often used are saccharin and cyclamate, with a sweetness level of 200-700 times the sweetness of sucrose while the sweetness level of cyclamate is 30 times that of sucrose, excessive use of saccharin and accumulates in the body so that it can trigger bladder tumors, allergies. This examination is to determine the levels of sodium saccharin and cyclamate in mixed cappuccino powder and unmixed cappuccino powder sold in the Tapos Depok area, West Java qualitatively and quantitatively using acid-base titration method for saccharin and Gravimetry for cyclamate. The results of the 10 samples all contained saccharin with the highest levels of saccharin in the cappuccino powder that had been mixed with sugar, namely with a level of $1154.95 \mathrm{mg} / \mathrm{kg}$. And it does not meet the requirements listed in Perka BPOM RI No. 4 of 2014, namely $100 \mathrm{mg} / \mathrm{kg}$, on the cyclamate sweetener, out of 10 samples, 4 samples show positive results. 2 samples did not meet the requirements according to Perka BPOM RI No. 4 of 2014, which exceeded $250 \mathrm{mg} / \mathrm{kg}$. Meanwhile, the results of the T Test for Saccharin showed that HO was accepted, which means that the levels of Saccharin in the cappuccino powder were mixed and not mixed together or there was no difference. On the cyclamate examination, the $\mathrm{HO}$ results were accepted, which means that the cyclamate content in the cappuccino powder was mixed and not mixed the same or there was no difference.

Keywords: Saccharin, Cyclamate, Acid-Base Titration and Gravimetry

Open Journal System (OJS): journal.thamrin.ac.id

http://journal.thamrin.ac.id/index.php/anakes/issue/view/34 


\section{PENDAHULUAN}

Pangan merupakan kebutuhan pokok manusia, yang terbagi menjadi makanan utama, penganan, buahbuahan dan golongan minuman (Winarno, 2004:54). Pangan juga merupakan segala sesuatu yang berasal dari sumber hayati produk pertanian, perkebunan, kehutanan, perikanan, peternakan, dan air, baik yang diolah maupun yang diperuntukkan sebagai makanan atau minuman bagi konsumsi manusia, termasuk bahan tambahan pangan, dalam proses penyiapan, pengolahan, dan atau pembuatan makanan atau minuman (Perka BPOM RI No. 4 Tahun 2014).

Es cappucino banyak digemari di masyarakat karena harganya yang murah dan rasanya yang enak. Namun pesatnya perkembangan tidak selalu diikuti oleh tingginya kualitas dari minuman ringan tersebut dan sebagian besar minuman ringan yang dijajakan merupakan industri rumahan yang dijual dengan kemasan sederhana, tanpa atau dengan label sederhana dan harganya relatif murah (Aminah, M. S., dan Himawan C., 2009:28).

Pemanis buatan yang dapat menyebabkan rasa manis pada makanan dalam bahan kimia yang dibuat secara sintesis yang karena rasa manisnya dapat digunakan untuk menggantikan gula tetapi hampir tidak mempunyai nilai gizi, bahan ini tidak boleh dipergunakan begitu saja untuk menggantikan gula makanan yang berkalori rendah atau makanan diet (Sukarwa, 1989:34).

Dari pengamatan yang telah penulis lakukan, terlihat bahan es cappucino merupakan minuman olahan industri rumahan, kemudian pada minuman es cappucino tersebut hanya dikemas dengan gelas plastik sederhana tanpa adanya pelabelan yang berisi komposisi bahan dan tanggal kadaluarsa.Selain itu, minuman ini juga dijajakan secara terbuka di pinggir jalan, sehingga dapat terkontaminasi oleh polutan dari kendaraan, debu dan oleh partikel-partikel dari asap (Aminah, M. S., dan Himawan C., 2009:28).

Pemanis buatan (sintesis) merupakan bahan tambahan yang dapat memberikan rasa manis dalam makanan, tetapi tidak memiliki nilai gizi (Yuliarti, 2007).

Sakarin adalah zat pemanis buatan yang dibuat dari garam natrium dari asam sakarin berbentuk bubuk kristal putih, tidak berbau dan sangat manis.Intensitas rasa manis garam natrium sakarin cukup tinggi, yaitu kira-kira 200-700 kali sukrosa 10\%. Di samping rasa manis, sakarin juga mempunyai rasa pahit yang disebabkan oleh kemurnian yang rendah dari proses sintesis (Cahyadi, 2012:82).

Siklamat atau cychlohexylsulfamic acid $\left(\mathrm{C}_{6} \mathrm{H}_{13} \mathrm{NO}_{3} \mathrm{~S}\right)$ sebagai pemanis buatan digunakan dalam bentuk garam kalsium, kalium, dan natrium siklamat. Secara umum, garam siklamat berbentuk kristal putih, tidak berbau, tidak berwarna, dan mudah larutan dalam air dan etanol, serta berasa manis (Cahyadi, 2012:84).

Pada bulan Maret sampai bulan Juni 2015 telah dilakukan penelitian oleh Irma Agustina tentang "Analisa Pemanis Sakarin pada Cappucino Cincau di Kecamatan Ciracas, Jakarta Timur 2015”. Dari analisis 
Anakes : Jurnal IImiah Analis Kesehatan Vol. 5 No. 2 ; September 2019 p-ISSN: 2088-5687 e-ISSN: $2745-6099$

sampel tersebut diperoleh jumlah 30 sampel cappucino serbuk di Ciracas terdapat 14 sampel yang mengandung Sakarin sedangkan 16 sampel sisanya tidak mengandung Sakarin. Dari 14 sampel yang diperiksa secara kuantitatif didapat 9 sampel melebihi batas penggunaan Sakarin. Sedangkan sisanya sebanyak 5 sampel masih memenuhi syarat dengan kadar tertinggi 642,79 mg/kg dan kadar terendah $221,01 \mathrm{mg} / \mathrm{kg}$.

Sedangkan efek yang dapat dtimbulkan akibat mengkonsumsi Sakarin dalam dosis yang lebih, mampu memutuskan plasenta pada bayi. Selain itu secara khusus pengkonsumsian Sakarin akan menimbulkan dampak dermatologis bagi anak-anak yang alergi terhadap sulfamat kemudian akan memicu tumbuhnya tumor yang bersifat karsinogen (Ambar Sari, 2011).

Hasil metabolisme Siklamat yaitu sikloheksilamin yang bersifat karsinogenik. Oleh karena itu, ekskresi Siklamat dalam urin dapat merangsang tumor. Pengkonsumsian Siklamat dalam dosis yang lebih akan mengakibatkan kanker kandung kemih (Ambar Sari, 2011).

Menyadari akan hal ini, bahwa efek karsinogenik yang akan di timbulkan oleh Sakarin dan Siklamat dapat merugikam konsumen, maka perlu di lakukan uji pada sampel serbuk cappucino yang sudah dicampur langsung dengan gula dan serbuk cappucinonya saja untuk melihat adakah kandungan Sakarin dan Siklamat di dalam sampel. Dimana sampel banyak di jual dikios yang terdapat di Tapos Depok juga banyak dikonsumsi oleh banyak kalangan di masyarakat termasuk penulis.

\section{METODE}

Penelitian dilakukan di Laboratorium Kimia Air, Makanan, dan Minuman (Kimia Amami) Universitas MH. Thamrin Jakarta. Waktu penelitian dimulai pada bulan 27 Juli - 3 Agustus tahun 2018. Populasi : Seluruh minuman cappucino yang di campur dan cappucino tidak di campur yang masih berbentuk serbuk yang di jual di sekitaran wilayah Tapos Depok Jawa Barat. Sampel Dari 8 kios penjual cappucino dalam bentuk serbuk di wilayah Tapos Depok Jawa Barat hanya diambil 5 sampel secara acak dari 8 kios. Sampel tersebut dilakukan pemeriksaan kadar Sakarin dan Siklamat dengan menggunakan metode Titrimetri (Asam Basa) dan metode Gravimetri. Hasil perhitungan Sakarin dan Siklamat di oleh menggunakan uji T yang bertujuan untuk melihat ada atau tidknya perbedaan kadar Sakarin dan Siklamat pada sampel cappucino yang dicampur dan tidak dicampur. 


\section{HASIL \& PEMBAHASAN}

Dari hasil pemeriksaan kadar Sakarin dan Siklamat yang telah dilakukan terhadap 10 sampel yang terdiri dari 5 serbuk cappucino yang sudah dicampur dengan gula dan 5 serbuk cappucino yang tidak dicampur dengan gula yang berada di sekitaran wilayah Tapos Depok Jawa Barat di dapatkan hasil sebagai berikut :

Tabel 1

Hasil Pemeriksaan Uji Kualitatif dan Kuantitatif Natrium Sakarin Dalam Serbuk Cappucino Yang Dicampur dan Tidak Dicampur

\begin{tabular}{cllll}
\hline \multirow{2}{*}{ No } & \multicolumn{1}{c}{$\begin{array}{c}\text { Nama Sampel Serbuk } \\
\text { Cappucino }\end{array}$} & \multicolumn{2}{c}{ Pemeriksaan Uji Natrium Sakarin } \\
\cline { 3 - 5 } & \multicolumn{2}{c}{ Uji Kualitatif } & Uji Kuantitatif \\
\hline 1 & Cappucino campur 1 & Positif $(+)$ & Ungu & $1096,30 \mathrm{mg} / \mathrm{kg}$ \\
\hline 2 & Cappucino campur 2 & Positif $(+)$ & Ungu & $731,15 \mathrm{mg} / \mathrm{kg}$ \\
\hline 3 & Cappucino campur 3 & Positif $(+)$ & Ungu & $559,37 \mathrm{mg} / \mathrm{kg}$ \\
\hline 4 & Cappucino campur 4 & Positif $(+)$ & Ungu & $408,83 \mathrm{mg} / \mathrm{kg}$ \\
\hline 5 & Cappucino campur 5 & Positif $(+)$ & Ungu & $1154,95 \mathrm{mg} / \mathrm{kg}$ \\
\hline 6 & Cappucino 6 & Positif $(+)$ & Ungu & $222,42 \mathrm{mg} / \mathrm{kg}$ \\
\hline 7 & Cappucino 7 & Positif $(+)$ & Ungu & $386,16 \mathrm{mg} / \mathrm{kg}$ \\
\hline 8 & Cappucino 8 & Positif $(+)$ & Ungu & $229,52 \mathrm{mg} / \mathrm{kg}$ \\
\hline 9 & Cappucino 9 & Positif $(+)$ & Ungu & $523,73 \mathrm{mg} / \mathrm{kg}$ \\
\hline 10 & Cappucino 10 & Positif $(+)$ & Ungu & $515,97 \mathrm{mg} / \mathrm{kg}$ \\
\hline
\end{tabular}

Dari tabel 1 diatas pada uji Kualitatif Natrium Sakarin di dapatkan hasil positif (+) sebanyak 10 sampel. Kemudian dilanjutkan dengan uji Kuantitatif di dapatkan hasil positif (+) dengan kadar terendah 222,42 $\mathrm{mg} / \mathrm{kg}$ sedangkan kadar tertinggi $1154,95 \mathrm{mg} / \mathrm{kg}$.

Tabel 2

Hasil Pemeriksaan Uji Kualitatif dan Kuantitatif Natrium Siklamat Dalam Serbuk Cappucino Yang Dicampur dan

Tidak Dicampur

\begin{tabular}{clcc} 
No & Nama Sampel Serbuk & \multicolumn{2}{c}{ Pemeriksaan Uji Natrium Siklamat } \\
\cline { 3 - 4 } & Cappucino & Uji Kualitatif & Uji Kuantitatif \\
\hline 1 & Cappucino campur 1 & Negatif $(-)$ & Tidak terjadi endapan \\
\hline 2 & Cappucino campur 2 & Negatif $(-)$ & Tidak terjadi endapan \\
\hline 3 & Cappucino campur 3 & Negatif $(-)$ & Tidak terjadi endapan \\
\hline 4 & Cappucino campur 4 & Negatif $(-)$ & Tidak terjadi endapan \\
\hline 5 & Cappucino campur 5 & Negatif $(-)$ & Tidak terjadi endapan \\
\hline 6 & Cappucino 6 & Positif $(+)$ & 208,11 mg $/ \mathrm{kg}$ \\
\hline 7 & Cappucino 7 & Negatif $(-)$ & Tidak terjadi endapan \\
\hline 8 & Cappucino 8 & Positif $(+)$ & $203,34 \mathrm{mg} / \mathrm{kg}$ \\
\hline 9 & Cappucino 9 & Positif $(+)$ & $1219,44 \mathrm{mg} / \mathrm{kg}$ \\
\hline 10 & Cappucino 10 & Positif $(+)$ & $361,62 \mathrm{mg} / \mathrm{kg}$
\end{tabular}


Dari tabel 2 diatas pada uji Kualitatif Natrium Siklamat di dapatkan hasil positif $(+)$ sebanyak 4 sampel. Kemudian dilanjutkan dengan uji Kuantitatif di dapatkan dengan kadar terendah 203,34 mg/kg sedangkan kadar tertinggi 1219,44 mg/kg.

Tabel 3

Hasil Uji T Sakarin dan Siklamat Pada Cappucino Yang Dicampur dan Tidak Dicampur

\begin{tabular}{ccc}
\hline Cappucino & \multicolumn{2}{c}{ P Value } \\
\hline $\begin{array}{c}\text { Cappucino dicampur dan } \\
\text { tidak dicampur }\end{array}$ & Sakarin & Siklamat \\
\cline { 2 - 3 } & 0,067 & 0,135 \\
\hline
\end{tabular}

Berdasarkan uji Sakarin diperoleh nilai signifikasi sebesar 0,067>0,05 maka $\mathrm{H}_{0}$ diterima yang berarti kadar Sakarin pada serbuk cappucino dicampur dan serbuk cappucino tidak dicampur yang dijual di Wilayah Tapos Depok Jawa Barat adalah sama atau tidak ada perbedaan.

Sedangkan pada uji Siklamat diperoleh nilai signifikasi sebesar 0,135 $>0,05$. Maka $\mathrm{H}_{0}$ diterima yang berarti bahwa kadar siklamat pada serbuk cappucino dicampur dan serbuk cappucino tidak dicampur yang dijual di Wilayah Tapos Depok Jawa Barat adalah sama atau tidak ada perbedaan.

Berdasarkan hasil penelitian terhadap serbuk cappucino yang dicampur dengan gula dan yang tidak dicampur dengan gula yang terdapat di sekitaran wilayah Tapos Depok Jawa Barat dari 10 sampel dilakukan pemeriksaan Sakarin dan Siklamat.

Dilakukan uji T pada pemeriksaan Sakarin didapatkan hasil signifikasi sebesar 0,067 > 0,05 maka $\mathrm{H}_{0}$ diterima yang berarti kadar Sakarin pada serbuk cappucino di campur dan serbuk cappucino tidak di campur yang di jual di Wilayah Tapos Depok Jawa Barat adalah sama atau tidak ada perbedaan. Sedangkan pada pemeriksaan Siklamat didapatkan hasil signifikasi sebesar 0,135 $>0,05$. Maka $\mathrm{H}_{0}$ diterima yang berarti bahwa kadar siklamat pada serbuk cappucino di campur dan serbuk cappucino tidak di campur yang dijual di Wilayah Tapos Depok Jawa Barat adalah sama atau tidak ada perbedaan.

Dari hasil penelitian yang diperiksa didapatkan hasil 10 sampel mengandung pemanis buatan Sakarin, dengan kadar terendah 222,42 mg/kg sedangkan kadar tertinggi 1154,95 mg/kg. Sehingga 10 sampel tidak memenuhi persyaratan dari batas maksimum penggunaan Sakarin menurut Perka BPOM RI No 4 Tahun 2014 yaitu $100 \mathrm{mg} / \mathrm{kg}$. Sedangkan untuk Siklamat didapatkan hasil 4 sampel (+) positif mengandung pemanis buatan Siklamat dengan kadar terendah sebesar 203,34 mg/kg dan kadar Siklamat tertinggi sebesar 1219,44 mg/kg. Sehingga didapatkan hasil dari 2 sampel yang mengandung Siklamat masih memenuhi persyaratan dan 2 lainnya tidak memenuhi persyaratan pada batas maksimum penggunaan menurut Perka BPOM RI No 4 Tahun 2014 yaitu $250 \mathrm{mg} / \mathrm{kg}$. Dari hasil yang telah diteliti, kandungan yang sangat tinggi melebihi persyaratan Perka BPOM RI No 4 Tahun 2014 terdapat pada 
kadar Sakarin dan Siklamat yaitu lebih dari $100 \mathrm{mg} / \mathrm{kg}$ untuk Sakarin, sedangkan $250 \mathrm{mg} / \mathrm{kg}$ untuk Siklamat, yang artinya melebihi penggunaan Sakarin dan Siklamat yang telah dianjurkan. Dan dari hasil penelitian oleh Ria Andani pada tahun 2016 dilakukan pemeriksaan terhadap 15 sampel serbuk cappucino didapatkan semua sampel positif $(+)$ mengandung Sakarin dan 1 sampel mengandung Siklamat. Dengan kadar Sakarin terendah sebesar 909,43 mg/kg dan kadar tertinggi sebesar 2821,12 mg/kg, sedangkan Siklamat di dapatkan hasil 1017,83 mg/kg.

Hal ini dikarenakan produsen ingin mendapatkan keuntungan dengan penggunaan Sakarin yang memiliki tingkat kemanisan lebih tinggi yaitu kurang lebih 300 kali rasa sukrosa. Namun ada pula kadar Sakarin pada sampel serbuk cappucino mengalami sedikit penurunan dalam penggunaannya menggambarkan bahwa penggunaan gula pasir murni yang harganya tidak melambung naik dalam penggunaannya bisa dicampurkan dengan Sakarin ke dalam serbuk cappucino.

Pada penggunaan Sakarin di atas batas maksimum yang diizinkan dalam jangka waktu yang lama akan berdampak negatif bagi kesehatan. Hal ini dapat dilihat berdasarkan penelitian yang telah dilakukan oleh FDA (Food and Drug Administration) terhadap hewan percobaan mendapatkan hasil bahwa Sakarin dapat menyebabkan kanker kandung kemih dengan dosis yang diberikan kepada hewan percobaan tersebut melebihi batas maksimal penggunaan, meskipun tergolong potensi rendah penyebab kanker kandung kemih terhadap manusia. Tertinggalnya Sakarin dalam tubuh karena tidak bisa di metabolisme oleh tubuh makan semakin lama akan mengalami penumpukan dalam tubuh yang menyebabkan kanker dalam kandung kemih ( Winarno, F . G., 1988:57-59).

Sedangkan pada Siklamat hasil metabolisme Siklamat yaitu sikloheksilamin yang bersifat karsinogenik.

Oleh karena itu, ekskresi Siklamat dalam urin dapat merangsang tumor dan mampu menyebabkan atropi, yaitu pengecilan testikular dan kerusakan kromosom. Pengkonsumsian Siklamat dalam dosis yang lenih akan mengakibatkan kanker kandung kemih.

Dari hasil penelitian pemeriksaan Kadar Sakarin dan Siklamat dapat disimpulkan bahwa masih ada beberapa sampel yang mengandung pemanis buatan baik Sakarin dan Siklamat dengan hasil kadar yang tinggi melebihi batas ketentuan syarat Peraturan Kepala Badan Pengawas Obat dan Makanan. Tingginya penggunaan pemanis buatan tersebut dikarenakan harganya yang sangat ekonomis, dengan harga biaya rendah membuat banyak pedagang lebih memilih penggunaan pemanis buatan dibandingkan dengan gula yang harganya lebih tinggi. Pada umumnya penggunaan Sakarin dan Siklamat secara bersamaan bertujuan untuk menutupi rasa pahit yang dihasilkan dari pemanis Sakarin dengan penambahan Siklamat. Jika penggunaan pemanis buatan Sakarin dan Siklamat secara berlebihan dengan melebihi batasan syarat 
Anakes : Jurnal IImiah Analis Kesehatan Vol. 5 No. 2 ; September 2019 p-ISSN: 2088-5687 e-ISSN: 2745-6099

BPOM akan menimbulkan efek samping diantaranya yaitu : sakit perut, sakit kepala, migrain, insomnia, hipertensi, diare, kanker otak, dan kanker kandung kemih.

\section{SIMPULAN}

Pemeriksaan kadar pemanis buatan Sakarin dengan kadar terendah 222,42 mg/kg sedangkan kadar tertinggi $1154,95 \mathrm{mg} / \mathrm{kg}$. Yang menunjukkan semua sampel tidak memenuhi syarat sesuai dengan ketentuan BPOM RI yaitu $100 \mathrm{mg} / \mathrm{kg}$. Sedangkan pada pemeriksaan pemanis buatan Siklamat didapatkan kadar terendah 203,34 mg/kg dan didapatkan kadar tertinggi 1219,44 mg/kg. Dinyatakan 2 sampel tidak memenuhi syarat dan 2 sampel yang masih memenuhi syarat Perka BPOM RI No 4 Tahun 2014 yaitu 250 $\mathrm{mg} / \mathrm{kg}$.Dari hasil uji $\mathrm{T}$ yang telah dilakukan pada sampel serbuk Cappucino dicampur gula dan tidak dicampur gula pada pemeriksaan Sakarin adalah didapatkan hasil signifikasi sebesar 0,067>0,05 maka $\mathrm{H}_{0}$ diterima yang berarti kadar Sakarin pada serbuk cappucino dicampur dan serbuk cappucino tidak dicampur yang di jual di Wilayah Tapos Depok Jawa Barat adalah sama atau tidak ada perbedaan. Sedangkan pada pemeriksaan Siklamat didapatkan hasil signifikasi sebesar 0,135 $>0,05$. Maka $\mathrm{H}_{0}$ diterima yang berarti bahwa kadar siklamat pada serbuk cappucino dicampur dan serbuk cappucino tidak dicampur yang dijual di Wilayah Tapos Depok Jawa Barat adalah sama atau tidak ada perbedaan.

\section{UCAPAN TERIMA KASIH}

Penulis mengucapkan terima kasih kepada Para Pedagang Capucino yang Seribu yang bersedia untuk penelitian ini dan Prodi D III Analis Kesehatan berperan serta dalam penelitian ini.

\section{DAFTAR PUSTAKA}

1. Ambar Sari, Indrie et.al., "Penerapan Standar Penggunaan Pemanis Buatan Pada Produk Pangan",dalam http://ebookkuliah.com/penerapan-standar-penggunaan-pemanisbuatan-padaproduk-pangan , 2011.

2. Aminah, M.S., dan Candra, H, Bahan-bahan Berbahaya dalam Kehidupan, Bandung, Salamadani, 2009.

3. Budiyanto, Krino, Gizi Pada Anak. In: Dasar-dasar Ilmu, 2nd ed. Ed: Universitas Muhammadiyah, UMM Press Malang, 2004. 
4. Cahyadi, Wisnu, Analisis dan Aspek Kesehatan Bahan Tambahan Pangan, Edisi Kedua, Bumi Aksara, Jakarta, 2008.

5. Cahyadi, Wisnu, Analisis dan Aspek Kesehatan Bahan Tambahan Pangan, PT Bumi Aksara, Jakarta, 2012.

6. Farmakope Indonesia Edisi IV Depkes 1995

7. Henny, Hikmah Wati, "Kadar Pemanis Buatan Pada Minuman Yang Dijual Di Sekolah Dasar Di Kecamatan Wonoayu Kabupaten Sidoarjo,” Tesis (Jakarta:JIPTUMMPP,) dalam http://library.walisongo.ac.id/digilib/files/disk1/119/jtptiain-gdl-dewilestar-5915-1073711019.pdf ,2004.

8. Info POM. vol. 9 No. 6 Tahun 2008

9. Irma, A, Analisa Sakarin pada cappucino cincau di Kecamatan Ciracas Jakarta Timur, Politeknik Kesehatan Jakarta III, Kementrian Kesehatan, Jakarta, 2015.

10. Ismail,Krisnadi, pengantar kimia analisis I (Gravimetri). Bogor. departemen perindustrian dan perdagangan, 2000.

11. Khopkar, S, M, Konsep Dasar Kimia Analitik. Jakarta : Universitas Indonesia, 1990.

12. Musiam, Siska, Penetapan Kadar Siklamat Dalam Sirup Merah Yang Dijual Di Banjarmasin Utara (Akademi Farmasi ISFI Banjarmasin), 2016.

13. Peraturan Kepala Badan Pengawas Obat dan Makanan RI No. 4 Tahun 2014.

14. Rahardjo, Pudji, Panduan Budidaya dan Pengolahan Kopi Arabika dan robusta, Penebar Swadaya, Jakarta, 2012.

15. Renawati, Iskandar, Teori Analisis Pemanis Buatan dalam Kumpulan makalah diklat analisis makanan dan minuman (Semarang: Balai Industri Semarang) dalam http://library.walisongo.ac.id/digilib/files/disk1/119/jtptiain-gdl-dewilestar-5915-1073711019.pdf, 2010.

16. Sri Najiyati dan Danarti, Budidaya Tanaman Kopi dan Penanganan Pasca Panen, Penebar Swadaya, Jakarta, 2004.

17. Sudjadi, Kimia Farmasi Analisis, Pustaka Pelajar, Yogyakarta, 2007.

18. Sukarwa, M, Persyaratan Pengaturan Penggunaan Pemanis Buatan, 1989.

19. Soerodo, Kimia Analitik Kualitatif Anorganik dan Kuantitatif, STIKes MH.Thamrin Jakarta, 1995. 
Anakes : Jurnal IImiah Analis Kesehatan Vol. 5 No. 2 ; September 2019 p-ISSN: 2088-5687 e-ISSN: 2745-6099

20. Winarno, F . G, Keamanan Pangan Jilid 1, M-BRIO PRESS, Bogor, 2004.

21. Vogel, Buku Teks Analisis Anorganik Kulitatif Makro dan Semimakro, PT.Kalman Media Pustaka, Jakarta, 1990.

22. Yuliarti, N. Awas! Bahaya Di balik Lezatnya Makanan. Yogyakarta:C. Vandi, 2007. 